\title{
Analyzing and Recommending Solutions for Effective Execution of RFID in Retail Sector
}

\author{
Jaspreet Kaur ${ }^{1}$, Dr. Gagandeep Jagdev ${ }^{2}$ \\ ${ }^{1}$ Research Scholar (M.Tech.), Yadavindra College of Engineering, Talwandi Sabo (PB) \\ ${ }^{2}$ Dept. of Comp. Science, Punjabi University Guru Kashi College, Damdama Sahib (PB)
}

*Corresponding Author: Dr. Gagandeep Jagdev, Dept. of Comp. Science, Punjabi University Guru Kashi College, Damdama Sahib (PB)

\begin{abstract}
RFID (Radio frequency identification) is a wireless technology making use of the waves in communication. RFID market is flourishing at a high pace. The utilization of RFID in the retail sector, government projects, and medical sector is already in full swing. With the assistance of RFID, objects can be easily tracked because of their connectivity with internet or databases. The basic components of RFID are RFID tags, RFID readers, and the central database stored in any computer system depending on the data it is supposed to handle. RFID finds its applications in different sectors like retail, traffic, and aid blind people in their movement. RFID technology has the potential to increase the profit of companies by improving the efficiency, accuracy, and security of the supply chain. It is because of this potential of RFID that numbers of companies are actively involved in testing and adopting this technology. It is for sure that in the coming future the market for RFID products and services is set for a huge leap. But as with every technology, there is another side of the coin pointing to certain hurdles that are faced in effective implementation of RFID technology. It has been few years since RFID systems came into existence but the technology for supply chain management is still emerging. The two bulging problems related to RFID are of tag collision and reader collision. The research paper focuses on an in-depth look at cost, technology, standards, privacy, security, and business process re-engineering related issues surrounding RFID technology.
\end{abstract}

Keywords: RFID, retail industry, reader, tags, wireless communication.

Abbreviations: $E P C, R F I D, U I D$.

\section{INTRODUCTION}

The RFID [1, 2, 5] technology makes use of radio waves to automatically identify items or people. Like smart cards, bar codes, and voice recognition, RFID is an automatic identification used to identify objects. But unlike bar codes, RFID is free from the constraints of the line of sight. It involves the use of automatic data capture systems for identifying objects and capturing information which is then transferred to the computer without needing to enter data manually.

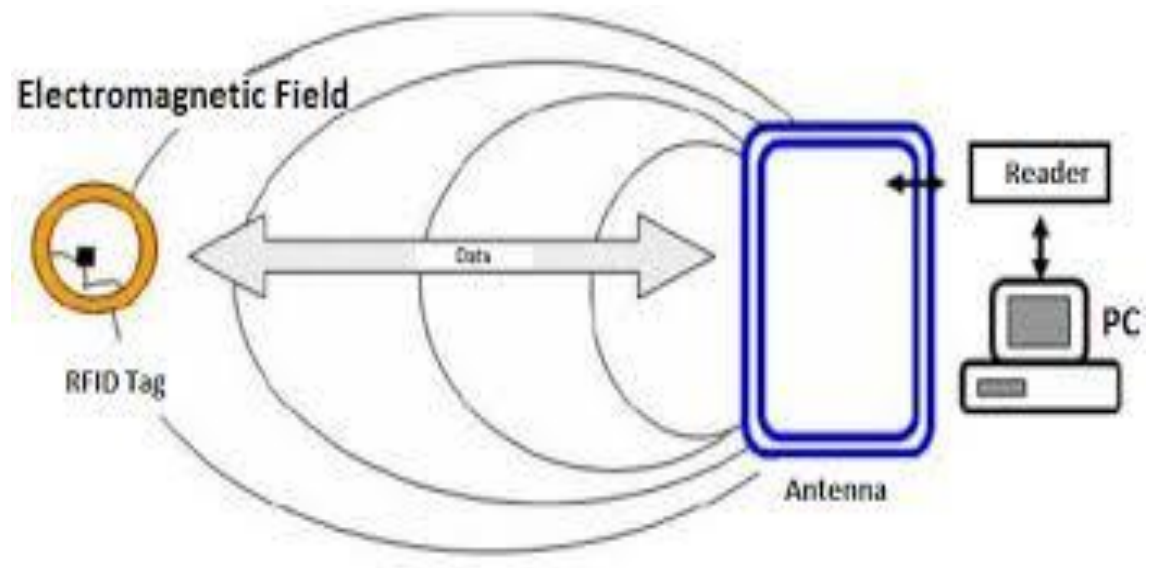

Fig1. Working of RFID 
Fig. 1 shows the working of RFID technology. The computer system captures the digital information contained in RFID tags via one or multiple RFID readers. RFID tag comprises a global UID (unique identification) and data fields organized in a standard way. The tag can be read easily irrespective of its orientation. It is free from restrictions of the line of sight. The RFID technology has overcome the myth that it does not work around water or metal $[14,16]$.

\section{COMPONENTS OF RFID}

Important components $[3,4,7]$ of a RFID system are:

1. An RFID reader (also called transceiver) with an antenna and a transceiver.

2. A transponder (also called a tag) that includes an antenna and a chip.

It is a common term for technologies that use radio waves to automatically identify people or objects [14]

- An interrogator or reader comprises a transceiver, antenna, and decoder. The transceiver receives the radio signals which are decoded by the decoder into a byte stream. The antenna is used to emit/receive radio signals.

- A transponder or tag comprises a microchip and a small antenna. The information supposed to be processed is written in the microchip. The antenna is used to emit/receive radio signals.

RFID technology enables to have real-time access to latest information relevant to different products at any point in the supply chain. EPC (Electronic Product Code) Global Network is the key component of RFID vision. The unique identification number enclosed in the tag is known as an EPC. In addition to this, it comprises additional information in which manufacturers and different organizations are interested. As the products travel through the supply chain, their location can be traced by monitoring the RFID tags placed on them.

This concept can be well illustrated by a simple example - RFID is a technology that allows things to be identified via radio waves. A RFID reader sends an interrogating question to a RFID tag (e.g. "who are you?"). The tag can then respond with an answer to the reader (e.g. I am product XYZ from company $\mathrm{ABC}$ ). All this process is carried out by electromagnetic waves. Radio waves can be transmitted directly through objects. More importantly, the radio waves carry with them a minute electrical current that can be used to power the tags, effectively turning them into very small, special purpose, computers. It's this power that the RFID tag uses to send the response to the RFID reader [6, $14,17]$.

\section{RFID IN RETAIL INDUSTRY}

The businesses today have been smart enough to appreciate the likely benefits of RFID to their bottom lines. Businesses can be made more capable by augmenting its information and technology infrastructure with the competence to sense what is happening in the real world. Consider an example of pharmaceutical companies. RFID technology enables companies to track the location of expensive medicines very closely. This avoids loss of goods due to theft and assures retailers that the drugs have been actually dispatched from the manufacturer. Some major giants making use of RFID are Department of Defense, European retailer Metro Group, and Procter and Gamble [14].

It is sure that some processes will actually require RFID in future. The pharmaceutical industry is all set to make utilization of RFID as pedigree information to prove the identity of the manufacturer of a drug and the route followed by it through the supply chain would be followed more strictly.

RFID applications can be classified as short range or long range. Long range applications comprise track and trace applications. Often it is noticed that companies apply utmost effort in knowing that what is present in their warehouse. With the assistance of RFID, companies can track each unit easily and effectively even long after it has left the factory. RFID ensures the safe transfer of all this data. The company enjoys the adequate control on the product's lifecycle. Many instances have been noticed where companies had to recall the entire product due to fault in a minor component. For instance, a car manufacturing company has been forced to recall its whole car for a minor defect in the air conditioning system of the car. RFID enables making such recalls more focused. A company can enjoy the privilege of enjoying healthier data about post-production of the car. A car is loaded with individually tagged components. The needful data can be collected from accident sites, repair shops, 
and even from garages. The faster and focused fault tracing can be enabled even within the factory. The companies following the practice of Just in Time (JIT), i.e. components are used when they are delivered and delivered just before being needed, often faces out of stock situations $[7,8,14]$.

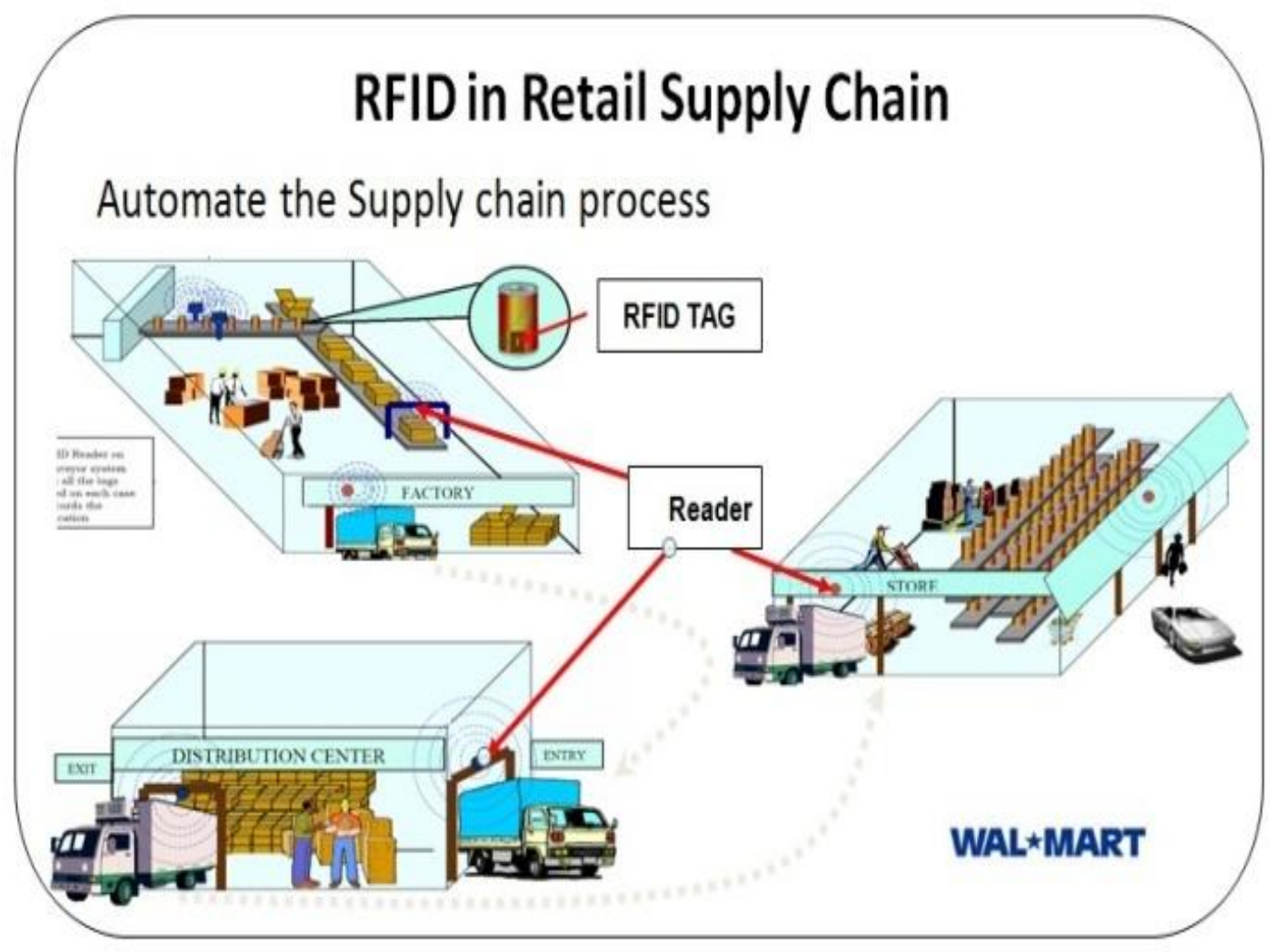

Fig2. Working with supply chain from manufacturer to customer

Goals of RFID in Retail industry

$>$ Decrease in lost stock

$>$ Faster locating stock

$>$ Lower labor requirement

$>$ Reduction of out-of-stock

$>$ Low safety stock level

$>$ Faster Checkouts

$>$ Better information

$>$ Faster payment

$>$ Reduced inventory requirements

$>$ Shipping errors

\section{Challenges Related to RFid}

There is no second thought in the fact that RFID has witnessed sizeable growth, but there are few serious concerns having relevance with RFID that needs to be addressed. Improved sensitivity of the tags and readers has enabled RFID to overpower some initial challenges but has also led to unexpected consequences. The sensitivity of chips, tags, and readers are much greater today [13, 14]. Every new technology faces up and downs and RFID is no exception. The prominent retailers like Adidas, Marks \& Spencer, Macy's have successfully deployed RFID in the apparel sector. RFID provides the range of efficiencies for retailers, comprising better margins based on lower level markdowns; growth in sales as a result of reduced out of stocks; and reduction in losses due to improved visibility. The major challenge faced by RFID is the price point of the tag. In case of passive RFID, the major challenge is the adoption of the change in business process to grab benefits 
delivered by RFID. For instance, many retailers perform complete physical inventory check once a year because of huge efforts involved in doing so. But with the assistance of RFID, the same inventory check process can be completed in few hours or even minutes. The challenge for retailers is to find out new methods to adapt pricing procedures, re-stocking, and merchandising to take optimal advantage of visibility offered by RFID. Besides retail, RFID also proved its worth in healthcare applications and supply chain optimization around perishable foods. RFID applications will witness dramatic increase as one pass through existing availability, functionality, tipping point of cost, and consumer expectations. RFID is definitely witnessing upswing [14].

The four major challenges $[9,10,12,14]$ that industry needs to deal with in regard to RFID adoption are discussed as under.

\section{A. Cost of Tags}

The cost of tags is the biggest hurdle in adopting passive Ultra High-Frequency tags. The price of tags is a big issue in open-loop applications. A tag is paid and affixed to an object by the user and shipped to another user which is outside the range of his or her system and finally loses the capability to obtain additional value from the tag under consideration. This fact can be supported via an example of supplier tagging a pallet prior it goes to end customer or distributor. The open-loop applications have certain constraints in implementation of RFID. But in closed-loop applications, the things are totally different because of numerous benefits as a tag is used over and over again.

\section{B. Industry Fragmentation and Segmentation}

RFID setup is not only limited to tags and readers. A complete RFID solution consists design, antennas, application software, enclosures, cabling, RFID middleware, tags, readers, tags, and installation services. It is somewhat like buying separate pieces of a vehicle and assembling it. With the involvement of multiple suppliers, the time required for completion of the project increases. Although efforts are being made by industry to ensure interoperability by employing certain standards, the problem will exist until a load of system design, installation and support is abolished from the end customer and merged with a single vendor.

\section{Cost of Infrastructure Replacement}

RFID has made several semiconductor companies active. These companies are considered responsible for bringing expertise in technology, physics, and chip-level design but however, they were short of system-level knowledge and experience of current practices in the auto-ID industry. Software engineers with sufficient experience in high-level application and database software attempted to bridge the gap within RFID middleware. But the software developed was expensive and had poor real-time performance [14, 17].

\section{Environmental Dependence}

Another hurdle in an effective implementation of RFID technology is its environmental dependence. Companies have removed the problems faced by tags in operating moisture or liquid or in the existence of metal. The services have improved to such an extent that now customers can send their items to the tag suppliers and choose their appropriate tag as per item and also the place where to place in the tag. However, when we consider infrastructure side, it is not possible for customers to send their shipping dock to decide the proper power settings, shielding requirements, selecting an antenna and angling them.

It refers to the fact that an experienced RFID technician should visit the site personally. Preferably customers procure this level of support at the earlier design stage in order to balance business processes and technological capabilities. It also allows selection of correct reader, antennas and solution form factor. Because these site-specific impacts have not been dealt properly, it has resulted in a failure of many projects and left many customers who showed faith in RFID technology unhappy. This factor alone has created much of negative publicity as far as RFID technology is concerned. So there is a need of better, experienced systems integrators and customer awareness of the importance of proper upfront design and installation support must be increased [14].

\section{E. Enabling Wider Adoption}

The rate of implementation of RFID has always been a disappointment. Rather than concentrating on RFID tag price reduction, the industry should focus on fixation of the underlying problems with deployment of appropriate infrastructure. 


\section{F. Forecasting Demand}

Retailers are always interested in knowing what products people will be buying and where the demand will be. This needs to gather demographic data and also the economic indicators to gain insight of spending habits of the public across the targeted market. For instance, it has been observed that during cold, the demand for books in south India witnessing an exponential increase. So, as per customer's feeds, the retailers increase the number of book recommendations.

\section{G. Identifying Customers}

The best way to increase the sale is to put the particular product in front of customers in the best way. For this retailers depend on recommending online technology and also the data gathered via transactional records and loyalty programs off and online. Concentration should be laid on the fact that how individual customers interact and make contact with retailers and decide the best way to interact with them for the promotion of the product, be it via email, SMS or any kind of mobile alert.

\section{APPROACHES For TACKLING SECURITY AND PRIVACY ISSUES}

There are a variety of solutions for tackling the security and privacy issues surrounding RFID. They can be categorized into the following areas $[11,12,14,16]$.

\section{Tag Data Protection}

\section{Reader Integrity}

\subsection{Solutions for Tag Data Protection}

\section{A. Password Protection on Tag Memory}

Whenever the talk is about security, the first word that strikes one's mind is password. Same is the case with RFID tags. The tag data can be protected by using appropriate passwords, preventing an unauthorized person from accessing the tag data. But the problem is that if all the tags have the same password, the chances of data becoming public are very high. However, if different passwords are planned for different tags, they need to be recorded, which means that reader would have to access the database multiple times and perform several comparisons for each reading performed.

\section{B. Physical Locking of Tag Memory}

The tag producer locks the sensitive information like unique identifier into the chip which is read-only during the manufacturing process. This authenticates the origin of the product. The problem with this method is that the privilege of rewriting is absent on such tag chips. Storage of extra information or modifying existing data would demand additional memory. This would end up in increased memory cost and larger memory size.

\section{Authentication of the "Author" in Tag Memory}

The author of the tag performs encryption of the tag data with his/her private key and places the encrypted data into the tag memory accompanied with author's name, a mention to his/her public key and the algorithm used in a non-encrypted form. When the authenticity of information needs to be verified, the retrieval of author's name and other non-encrypted information is conducted to assure that the data has been actually written by an authorized author. However, a key management system would be required if the RFID reader needs to update new data into the tag.

\subsection{Solutions for Rfid Reader Integrity}

\section{A. Reader Protection}

The tag replies with irregularities in signal power levels or response times can be rejected by the reader which doesn't match with the physical properties of tags. Spoofing attempts can be minimized with the use of passive tags. Readers can make use of random frequencies with the tags intended to follow the particular frequency dictated by the reader. The frequencies can witness random changes as desired by the reader to avoid unauthorized user eavesdropping on traffic.

Above this, the reader's identity could be asked whenever there is a need to transmit data between the reader and the RFID application server. An authentication process could be applied between backend application and reader to further ensure that valid processor receives the information. 


\section{B. Read Detectors}

RFID environments can be armed with superior devices to notice unapproved read attempts or transmissions on tag frequencies. The job of read detectors is to detect unauthorized read/update attempts on tags if their use is made with specially designed tags that are enabled to transmit signals over earmarked frequencies, representing attempts to kill or modify tags.

\section{CONCLUSION}

RFID technology has been recognized in different sectors and is all set to revolutionize the retail industry. Numerous industries and firms are already either testing or implementing different RFID applications. Four major benefits of using RFID in the retail supply chain is: (a) improved inventory management, (b) velocity of retail cycle, (c) integrated business model for inventory and supply chain management, and (d) improved store operation. Additionally, three critical risk factors for implementing RFID in the retail industry are (a) lack of expertise, (b) complexity of technology, and (c) uncertainty of technology. So the pros and cons of the above research can be summarized as mentioned below $[14,15]$.

\section{Pros:}

(1) Real-time data on assets and goods

(2) Increased data and knowledge for decision making

(3) Reduced theft and loss

(4) Improved inventory efficiency and management

(5) Reduced labor costs

(6) Increased efficiency and product flow

(7) Goods authentication

(8) Improved risk mitigation

(9) Reduced human error.

Cons:

(1) High implementation cost

(2) Lack of globally accepted use standards

(3) Lack of better middleware

(4) Privacy intrusion

(5) Strain in the IT infrastructure by overwhelming information systems as real-time scans move between multiple applications.

\section{REFERENCES}

[1] DD Donno, V Lakafosis, L Tarricone, MM Tentzeris, in Proceedings of IEEE MTT-S Int.Microwave Symp. Digest (MTT). Increasing performance of SDR-based collision-free RFID systems (Montreal, Canada, 17-22 June 2012).

[2] S Kim, S Kwack, S Choi, BG Lee, in Proceedings of 17th Asia-Pacific Conf. Communications (APCC). Enhanced collision arbitration protocol utilizing multiple antennas in RFID systems (Kota Kinabalu, Malaysia, 2-5 Oct 2011).

[3] J Kaitovic, R Langwieser, M Rupp, in Proceedings of IEEE International Conference on RFIDTechnologies and Applications (RFID-TA). RFID reader with multi antenna physical layer collision recovery receivers (Sitges, Spain, 15-16 Sept 2011).

[4] J Kaitovic, M `Simko, R Langwieser, M Rupp, in Proceedings of 2012 IEEE International Conference on RFID (RFID). Channel estimation in tag collision scenarios (Orlando, Florida, 3-5 April 2012).

[5] K Fyhn, RM Jacobsen, P Popovski, A Scaglione, T Larsen, Multipacket reception of passive UHF RFID tags: a communication theoretic approach. IEEE Trans Signal Process. 59(9), 4225-4237 (2011).

[6] J Myung, W Lee, J Srivastava, Adaptive binary splitting for efficient RFID tag anti-collision. IEEE Commun. Lett. 10(3), 144-146 (2006). 
[7] Y Cui, in Proceedings of IEEE International Conference on RFID-Technologies and Applications (RFID$T A$ ). System efficiency of collision recover binary tree algorithm in RFID (Nice, France, 5-7 Nov 2012).

[8] A Lazaro, D Girbau, D Salinas, Radio link budgets for UHF RFID on multipath environments. IEEE Trans. antennas Propag. 57(4), 1241-1251 (2009).

[9] Ke-Sheng Wang , Intelligent and integrated RFID (II-RFID) system for improving Traceability in manufacturing, Shanghai University and Springer-Verlag Berlin Heidelberg 2014

[10] Wei Xie, Lei Xie, Chen Zhang, Qiang Wang, Jian Xu, Quan Zhang, Chaojing Tang, RFID seeking: Finding a lost tag rather than only detecting its missing, Elsevier, Journal of Network and Computer Applications 42 (2014) 135-142.

[11] Jerrel Leung, Waiman Cheung, Sung-Chi Chu, Aligning RFID applications with supply chain strategies, Elsevier, Information \& Management 51 (2014) 260-269.

[12] Ilias P. Vlachos, A hierarchical model of the impact of RFID practices on retail supply chain performance, Elsevier, Expert Systems with Applications 41 (2014)

[13] Ming K. Lim, , Witold Bahr, Stephen C.H. Leung, RFID in the warehouse: A literature analysis (1995-2010) of its applications, benefits, challenges and future trends, Elsevier, Int. J. Production Economics 145 (2013) 409-430.

[14] Gagandeep Jagdev et al., "Exercising RFID in retail sector for economic growth and enhanced customer satisfaction", International Journal of Advanced Research in Computer Science (IJARCS), Volume 7, Issue 6, November 2016, Budhlada (India).

[15] Gagandeep Jagdev et al., "Scrutinizing Working and Proposing Solutions to Security Issues Involved in Retail RFID", International Journal of Scientific and Technical Advancements (IJSTA), ISSN-2454-1532, 2016.

[16] Gagandeep Jagdev et al., "A Study on implementation of RFID and sensors in Automotive Industry”, International Journal on Advanced Computer Theory and Engineering (IJACTE), ISSN: 2319-2526, Volume-4 Issue-5, 2015, sponsored by IRD, India.

[17] Gagandeep Jagdev et al., "Modern Cars ensures safety of human life via implementation of RFID and Sensors", International Journal of Scientific and Technical Advancements (IJSTA), ISSN-2454-1532, 2015.

\section{AUTHOR'S BIOGRAPHY}

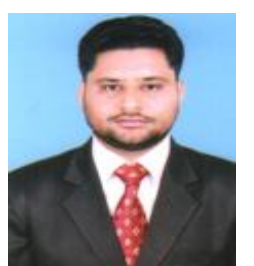

Dr. Gagandeep Jagdev, is a faculty member in Dept. of Computer Science, Punjabi University Guru Kashi College, Damdama Sahib (PB). His total teaching experience is above 10 years and has above 108 international and national publications in reputed journals and conferences to his credit. He is also a member of editorial board of several international peer-reviewed journals and has been active Technical Program Committee member of several international and national conferences conducted by renowned universities and academic institutions. His field of expertise is Big Data, ANN, Biometrics, RFID, Cloud Computing, Cryptography, and VANETS.

Citation: Jaspreet Kaur \& Dr. Gagandeep Jagdev (2017). Analyzing and Recommending Solutions for Effective Execution of RFID in Retail Sector, International Journal of Research Studies in Computer Science and Engineering (IJRSCSE), 4(3), pp.16-22, DOI: http://dx.doi.org/10.20431/2349-4859.0403003

Copyright: (C) 2017 Jaspreet Kaur\& Dr. Gagandeep Jagdev. This is an open-access article distributed under the terms of the Creative Commons Attribution License, which permits unrestricted use, distribution, and reproduction in any medium, provided the original author and source are credited 